\title{
INEQUALITIES FOR THE SCHWAB-BORCHARDT MEAN AND THEIR APPLICATIONS
}

\author{
EDWARD NEUMAN
}

Abstract. Inequalities for the Schwab-Borchardt mean are obtained. They contain known results for the trigonometric and hyperbolic functions including those obtained by J. Wilker [15] and C. Huygens [5]. The main results of this paper can also be utilized to obtain new inequalities for some bivariate means including the logarithmic mean and two means introduced by Seiffert.

Mathematics subject classification (2010): Primary: 26D05, 26D07, 33B10.

Keywords and phrases: The Schwab-Borchardt mean, trigonometric functions, hyperbolic functions, logarithmic mean, Seiffert means, inequalities.

\section{REFERENCES}

[1] J. M. Borwein, P. B. Borwein, Pi and the AGM: A Study in Analytic Number Theory and Computational Complexity, John Wiley and Sons, New York, 1987.

[2] P. S. Bullen, A Directory of Inequalities, Pitman Monographs and Surveys in Pure and Applied Mathematics, vol. 97, Addison Wesley Longman Limited, Longman, Harlow, 1998.

[3] B. C. CARLSON, Algorithms involving arithmetic and geometric means, Amer. Math. Monthly 78 (1971), 496-505.

[4] B.-N. GUO, B.-M. QIAO, F. QI, W. LI, On new proofs of Wilker inequality involving trigonometric functions, Math. Inequal. Appl. 6, 1 (2003), 19-22.

[5] C. Huygens, Oeuvres Completes 1888-1940, Sociéte Hollondaise des Science, Haga.

[6] D. S. Mitrinović, Analytic Inequalities, Springer-Verlag, Berlin, 1970.

[7] E. Neuman, One- and two-sided inequalities for Jacobian elliptic functions and related results, Integral Transform. Spec. Funct. 21, 6 (2010), 399-407.

[8] E. NeUman, Inequalities involving inverse circular and inverse hyperbolic functions II, J. Math. Inequal. 4, 1 (2010), 11-14.

[9] E. Neuman, On Wilker and Huygens type inequalities, Math. Inequal. Appl, to appear.

[10] E. Neuman, J. SÁndor, On the Schwab-Borchardt mean, Math. Pannon. 14, 2 (2003), 253-266.

[11] E. Neuman, J. SÁndor, On the Schwab-Borchardt mean II, Math. Pannon. 17, 1 (2006), 49-59.

[12] E. NEUmAn, J. SÁNDOR, On some inequalities involving trigonometric and hyperbolic functions with emphasis on the Cusa-Huygens, Wilker and Huygens inequalities, Math. Inequal. Appl. 13, 4 (2010), $715-723$

[13] H.-J. SeIFFERT, Problem 887, Nieuw. Arch. Wisk. 11 (1993), 176.

[14] H.-J. SEIFFERT, Aufgabe 16, Wurzel 29 (1995), 87.

[15] J. B. WILKER, Problem 3306, Amer. Math. Monthly 96 (1989), 55.

[16] S.-H. Wu AND A. BÁRICZ, Generalizations of Mitrinović, Adamović and Lazarević inequalities and their applications, Publ. Math. Debrecen 75, 3-4 (2009), 447-458.

[17] S.-H. WU AND H. M. SRIVASTAVA, A weighted and exponential generalization of Wilker's inequality and its applications, Integral Transform. and Spec. Funct. 18, 8 (2007), 525-535.

[18] L. ZHU, A new simple proof of Wilker's inequality, Math. Inequal. Appl. 8, 4 (2005), 749-750.

[19] L. ZHU, On Wilker-type inequalities, Math. Inequal. Appl. 10, 4 (2007), 727-731. 